\title{
Effect of fast dietary proteins on muscle protein synthesis rate and muscle strength in ad libitum-fed and energy-restricted old rats
}

\author{
Stéphane Walrand*†, Aude Zangarellit, Christelle Guillet, Jérôme Salles, Karine Soulier, \\ Christophe Giraudet, Véronique Patrac and Yves Boirie \\ INRA, UMR 1019, Unité de Nutrition Humaine, Clermont-Ferrand, F-63000, France; CRNH Auvergne, Clermont-Ferrand, F- \\ 63000, France; CHU Clermont-Ferrand, F-63000, France
}

(Received 22 January 2011 - Revised 22 March 2011 - Accepted 28 March 2011 - First published online 21 June 2011)

\begin{abstract}
Sarcopenia is defined as age-related loss of muscle mass and strength. Energy restriction (ER) delays fibre loss by limiting the accumulated deleterious effects of reactive oxygen species on muscle. However, insufficient protein intake during ER might affect muscle mass and function. We hypothesised that ingestion of fast-digested proteins such as whey protein (WP) improves muscle protein synthesis and muscle strength in aged ER rats. The effect of WP or casein (CAS, slow protein) on muscle mass, protein synthesis and strength was evaluated in 21-month-old rats fed for 5 months either ad libitum (AL) or a $40 \%$ protein and energy-restricted (PER) or $40 \%$ AL-isonitrogenous ER diet. The nitrogen balance was reduced in PER-CAS rats only $(-48 \% v$. AL-CAS). WP stimulated muscle protein synthesis rates compared with CAS in all groups $(+21,+37$ and $+34 \%$ in AL, PER and ER conditions, respectively). Muscle strength was higher in ER rats than in AL rats $(+23$ and $+12 \%$ for WP or CAS, respectively). Muscle performance tended to be greater in ER rats fed WP than in ER-CAS rats $(P<0 \cdot 09)$. In conclusion, we observed that long-term ER combined with maintained protein intake had a beneficial impact on muscle protein synthesis rate and function during ageing.
\end{abstract}

Key words: Energy restriction: Whey protein: Casein: Skeletal muscle: Sarcopenia

One of the most striking effects of ageing is an involuntary loss of muscle mass known as sarcopenia. Muscle loss in the elderly is the result of both reduced physical activity and insufficient food intake, in particular proteins, and age-related changes in muscle metabolism. Sarcopenia is a process resulting from the complex interplay of molecular and cellular changes $^{(1-3)}$. It has been suggested that, in addition to reduced physical activity and insufficient protein intake, one of the main causes of sarcopenia is the age-related decline in the synthesis rate of specific proteins in skeletal muscle. Indeed, fractional synthesis rates of myofibrillar proteins ${ }^{(4)}$, myosin heavy chain ${ }^{(5)}$ and mitochondrial proteins ${ }^{(6)}$ are reduced in older humans, especially in response to various anabolic stimuli such as administration of insulin and amino acids (AA) or intake of a complete meal ${ }^{(7-11)}$. These data provide evidence of a disturbed response of protein metabolism to AA availability with ageing ${ }^{(8,12)}$. Several studies support the notion that AA availability is the major regulating factor of protein synthesis. Consequently, the digestion rate of dietary proteins could influence protein gain by inducing variable peripheral availability of $\mathrm{AA}^{(13-15)}$. Other studies support the idea that essential AA, such as leucine, are necessary to stimulate muscle protein synthesis, and suggest that a protein able to provide a high proportion of these AA would be efficient in promoting muscle anabolism ${ }^{(8,16,17)}$. Therefore, both a rapid rate of digestion and absorption (fast proteins) and a high protein quality score lend whey protein (WP) advantages in terms of muscle anabolism. After WP ingestion, plasma appearance of dietary AA is fast, high and transient ${ }^{(13)}$. In young subjects, casein (CAS) displayed a better net leucine balance than $\mathrm{WP}^{(13)}$, showing that net AA retention is dependent on protein quality. This relationship may reverse during the ageing process, as shown previously (18). However, recent data have shown that the subsequent muscle protein synthetic response following the ingestion of a large bolus of intact CAS is not substantially impaired in healthy elderly men ${ }^{(19,20)}$. In addition, exercising before protein intake allowed for a greater use of dietary protein-derived AA for de novo muscle protein synthesis in healthy young and elderly men ${ }^{(21)}$. Taken together, these data show that there

\footnotetext{
Abbreviations: AA, amino acid; AL, ad libitum; ASR, absolute synthesis rate; CAS, casein; ER, energy restriction; PER, protein and energy restriction; WP, whey protein.
}

* Corresponding author: Dr S. Walrand, fax +33 473608255, email swalrand@clermont.inra.fr

†S. W. and A. Z. contributed equally to this work. 
is evidence that elderly muscle responds similarly to that of young muscle following anabolic stimuli such as high protein intake and exercise.

WP contains a relatively high proportion of essential and branched-chain AA compared with other major milk proteins. In this regard, the abundance of leucine content in WP is of particular interest, since leucine may act as an active modulator of protein synthesis by stimulating specific targets in the initiation factor pathway ${ }^{(8,22,23)}$. Consequently, WP might be beneficial for limiting whole-body protein losses during ageing, as already shown in elderly men ${ }^{(18)}$. However, there are still questions over the sparing effect of WP on skeletal muscle protein in the long term and with variable energy intake.

It is well known that insufficient protein intake, such as during energy restriction (ER), might affect muscle mass and function, particularly in aged individuals. Accordingly, we have previously shown ${ }^{(24)}$ that ER with maintained protein intake helps limit the progression of sarcopenia by optimising the turnover rates and functions of major proteins in skeletal muscle. However, whether the quality of dietary proteins, i.e. fast or slow dietary proteins, has an impact on the beneficial effect of ER on skeletal muscle metabolism in aged rats still remains to be determined.

In the present study, we addressed the hypothesis that ingestion of fast dietary proteins, i.e. WP, during the course of long-term ER safeguards the muscle mass and function of aged rats. We aimed to use these nutritional strategies combining WP intake with ER to take advantage of the beneficial well-known effects of both fast protein and ER on protein synthesis rate in muscles. To address this hypothesis, we compared the nitrogen balance, mass and synthesis rates of total protein in skeletal muscle of rats fed an ER diet containing either WP or CAS on a long-term basis, i.e. 5 months. We also examined whether this nutritional intervention is able to improve muscle force in aged rats.

\section{Experimental methods}

\section{Animals}

The French Animal Care and Use Committee approved the protocol before starting. Animal care and handling were in accordance with the National Institutes of Health guidelines for the use of experimental animals. Male Wistar rats were purchased from Janvier (Le Genest St Isle, France).

\section{Experimental protocol}

Male Wistar rats (21 months old) were maintained on a standard chow diet for 2 weeks. Daily food intake and body weight were measured during this adaptation period, and body weight was recorded twice a week throughout the experiment.

The rats were randomly assigned to one of the six dietary groups ( $n 10$ animals, Table 1 ) for 5 months. Working with this same strain of rats, we have recently reported a strong degree of skeletal muscle atrophy at 21 months of age compared with young adult rats, i.e. 4 months old ${ }^{(21)}$. A marked decline in the weight of type II muscles, e.g. tibialis anterior, has been reported previously ${ }^{(21)}$, showing that these animals are in a sarcopenia trajectory at 21 months of age.

In the present study, two control groups were allowed ad libitum (AL) access to a semi-liquid control diet consisting of $17 \%$ protein (CAS or WP for AL-CAS or AL-WP groups, respectively), 14\% fat and 69\% carbohydrate (Table 1). On average, AL consumption provided an energy intake of $440 \mathrm{~kJ} / \mathrm{d}$. Protein and energy-restricted (PER)-CAS and PERWP groups were fed with $60 \%$ of the food intake of AL control rats on the semi-liquid control diet containing either CAS or WP, respectively. ER-CAS and ER-WP groups were also limited to $60 \%$ of the energy intake of $\mathrm{AL}$ control rats but received similar daily CAS or WP intake, respectively, to those of the control animals. The mineral and vitamin contents of the four ER diets were increased to ensure equivalent intake between rats (Table 1). All animals had free access to water and were housed individually in plastic cages at $22 \pm 1{ }^{\circ} \mathrm{C}$ with light on from 08.00 to 20.00 hours. The rats were fasted $(8 \mathrm{~h})$ at the time of euthanasia. At the end of the experiment, the rats were anaesthetised with isoflurane and euthanised by decapitation. Immediately after death, skeletal muscles (tibialis anterior and soleus) and abdominal adipose tissue were collected, weighed, frozen in liquid $\mathrm{N}_{2}$ and stored at $-80^{\circ} \mathrm{C}$ until analysis.

\section{Nitrogen balance}

At 1 week before euthanasia, the old rats were placed individually in metabolic cages for $72 \mathrm{~h}$. Nitrogen balance was measured during the last $24 \mathrm{~h}$. During this period, food intake precisely was measured, and cumulated faeces and urines were collected on ice. Total nitrogen in urine was

Table 1. Diet composition and total daily intake in ad libitum (AL)-fed, protein and energy-restricted (PER) and energy-restricted (ER) aged rats receiving whey proteins (WP) or casein (CAS) as the protein source

\begin{tabular}{lcccccc}
\hline Component $(\mathrm{g} / \mathrm{d})$ & AL-CAS & AL-WP & PER-CAS & PER-WP & ER-CAS & ER-WP \\
\hline CAS & 4.73 & 0 & 2.87 & 0 & 4.73 & 0 \\
WP & 0 & 4.73 & 0 & 2.87 & 0 & 4.73 \\
Leu & 0.375 & 0.535 & 0.225 & 0.321 & 0.375 & 0.535 \\
Maize starch & 12.43 & 12.43 & 6.35 & 6.35 & 5.11 & 5.11 \\
Sucrose & 6.20 & 6.20 & 3.19 & 3.19 & 2.56 & 2.56 \\
Cellulose & 1.25 & 1.25 & 1.27 & 1.27 & 1.27 & 1.27 \\
Groundnut and colza oils & 1.69 & 1.69 & 1.69 & 1.69 & 1.69 & 1.69 \\
Mineral mix & 1.25 & 1.25 & 1.26 & 1.26 & 1.26 & 1.26 \\
Vitamin mix & 0.28 & 0.28 & 0.28 & 0.28 & 0.28 & 0.28 \\
Total daily intake & 27.83 & 27.83 & 16.91 & 16.91 & 16.90 & 16.90 \\
\hline
\end{tabular}


measured by chemiluminescence (Antek 7000, Alytech, Juvisysur-Orge, France) and by the Kjeldhal method in faeces and food, as described previously ${ }^{(23)}$. The nitrogen balance was calculated as the difference between nitrogen intake and nitrogen excretions in urine and faeces.

\section{In vivo muscle protein synthesis}

In vivo muscle protein synthesis rates were measured using the flooding dose method ${ }^{(24)}$. At the end of the study period, each rat was injected intravenously with a large dose of $\mathrm{L}_{-}\left[{ }^{13} \mathrm{C}\right]$ valine $(99 \mathrm{at} \% ; \quad 300 \mu \mathrm{mol} / 100 \mathrm{~g}$ body weight, Cambridge Isotope Laboratories, Andover, MA, USA) to flood the protein synthesis precursor pool ${ }^{(25,26)}$. The enrichment of the flooding dose was 50 at $\%$ excess. The rats were euthanised $50 \mathrm{~min}$ after the tracer infusion.

Pieces of tibialis anterior were used to isolate mixed proteins as described previously ${ }^{(26)}$. Briefly, after isolation, muscle proteins were hydrolysed using $6 \mathrm{M}-\mathrm{HCl}\left(110^{\circ} \mathrm{C}\right.$ for $\left.24 \mathrm{~h}\right)$, and the constituent AA were purified by cation exchange chromatography (Dowex 50W 8X; Bio-Rad Laboratories, Hercules, CA, USA). AA were eluted in $4 \mathrm{ml}$ of $4 \mathrm{M}-\mathrm{NH}_{4} \mathrm{OH}$ and dried down in a SpeedVac (Savant Instruments, Inc., Holbrook, NY, USA). AA were derivatised as their $N$-acetyl-propyl derivative. $\mathrm{L}-\left[{ }^{13} \mathrm{C}\right]$-valine enrichment was measured using a GC-combustion-isotope ratio MS system (GC-C-IRMS, $\mu$ Gas System; Fisons Instruments, VG Isotech, Middlewich, UK).

Muscle tissue fluid was separated as described previously ${ }^{(7)}$. AA in the tissue fluid were derivatised as their $t$-butyldimethylsilyl ester, and $\mathrm{L}_{-}\left[{ }^{13} \mathrm{C}\right]$ valine enrichments were measured using GC-MS (GC-MS, HP 5972; Hewlett Packard, Palo Alto, CA, USA) and used as precursor pool enrichment to calculate absolute synthesis rates (ASR) ${ }^{(7)}$. Another set of four rats per regimen was used for the determination of basal isotopic abundance in muscle proteins.

ASR of proteins was calculated using the following equation:

$$
\left.\operatorname{ASR}(\mathrm{mg} / \mathrm{d})=(((\mathrm{Eit}-\mathrm{Ei} 0) \times 100)) /\left(\mathrm{Ei}_{\text {prec }} \times t\right)\right) \times \mathrm{TPC},
$$

where Eit represents the enrichment as at $\%$ excess of ${ }^{13} \mathrm{C}$ derived from valine in proteins at time $t$ (minus basal enrichment $\mathrm{Ei} 0), \mathrm{Ei}_{\text {prec }}$ is the mean enrichment in the precursor pool (tissue fluid $\left[{ }^{13} \mathrm{C}\right]$ valine), $t$ is the incorporation time in $\mathrm{h}$ and TPC is the total muscle protein content in $\mathrm{mg}$.

\section{Muscle strength}

At 2 weeks before the end of the study, forelimb grip force was measured using a grip force meter $^{(27)}$ designed to measure the muscle strength of rodents. A force gauge, located at the front of the machine, was employed to measure this parameter. During testing, each rat was held by its tail and gently moved in a rostral-caudal direction in order to apply force to the mesh grid. After the gauge was zeroed, the rat was positioned with both forepaws inside the front grip grid. When the rat gripped the grid, it was steadily pulled backward by the tail until its grip was broken. The gauge converts forelimb grip force to a digitised signal that is displayed online. The reading on the gauge was recorded $(\mathrm{N})$, the strain 
gauge was zeroed, and the rat was retested until three successive readings were obtained. These measurements were repeated $3 \mathrm{~d}$ in a week. Comparisons between the amplitude of strength exerted by different animal groups were performed.

\section{Statistical analysis}

All data are presented as means with their standard errors of the mean. A two-way ANOVA was performed to test the effect of the experimental nutritional conditions, i.e. protein (WP/CAS) and group (AL/PER/ER). When a significant effect was detected, a posteriori Fisher's test was applied to locate pair-wise differences between groups. StatView software (version 4.02; Abacus Concepts, Berkeley, CA, USA) was used for the statistical analyses. Values of $P<0.05$ were considered as significant.

\section{Results}

\section{Body and muscle weights}

Final body and muscle weights are shown in Table 2. As expected, the ER rats weighed approximately $80 \%$ of the $\mathrm{AL}$ rats at the time of experimentation, regardless of the source and amount of proteins in the restricted diet $(P<0 \cdot 0001)$.

As expected, adipose tissues were largely lost after the ER period, whatever the group (a seven- to fifteen-fold reduction, $P<0.0001 v$. the corresponding AL groups). Of note, old ER-CAS rats displayed a greater adipose tissue loss than their PER-CAS counterparts $(P<0 \cdot 05)$.

Weights $(\mathrm{mg})$ of soleus muscle were not statistically different between groups, although soleus muscle weight tended to be higher in the AL-WP group compared with that in the AL-CAS group $(+13 \% ; P=0 \cdot 07)$. After 5 months of experimentation, tibialis anterior muscles weighed 9 and $7 \%$ less in PER-CAS and ER-CAS rats, respectively, compared with AL-CAS rats $(P<0 \cdot 01)$. WP ingestion combined with protein-energy or ER, i.e. WP-PER and WP-ER groups, prevented the loss of tibialis anterior muscle weight. Consequently, no significant differences were observed between AL-WP, PERWP and ER-WP groups at 5 months (Table 2). Tibialis anterior muscle-to-body mass ratio was unchanged regardless of group (Table 2). Conversely, soleus muscle:body mass ratio tended to be higher $(+12 \%)$ in $\mathrm{AL}-\mathrm{WP}$ rats $(P=0.09 v$. AL-CAS $)$ and was significantly higher in the ER groups, regardless of dietary protein source and quantity, due to the decrease in body weight $(P<0 \cdot 01)$.

\section{Nitrogen balance}

Under AL conditions, the nitrogen balance did not differ between AL-CAS and AL-WP diets (Table 3). After PER, PER-WP animals showed no further changes, whereas nitrogen balance was significantly reduced in the PER-CAS group $(-48 \%, P<0.05 v$. AL-CAS). As a result, nitrogen balance was higher in the PER-WP rats than in the PER-CAS rats $(P<0.05)$. The nitrogen balance was increased by ER compared with PER, regardless of the dietary protein source used $(+56 \%$ ERCAS $v$. PER-CAS and $+27 \%$ ER-WP $v$. PER-WP, $P<0 \cdot 05)$.

\section{Muscle protein synthesis}

We found a marked reduction in tibialis anterior ASR under ER and PER conditions, regardless of the dietary protein source $(-28$ to $-67 \%, P<0.01 v$. the corresponding AL groups, Table 3). A substantial positive effect of WP on muscle protein ASR was observed in the tibialis anterior muscle. WP significantly increased the ASR of mixed proteins by 21, 37 and $34 \%$ in $\mathrm{AL}$, PER and ER old rats, respectively $(P<0.05 v$. the corresponding CAS group).

\section{Muscle strength}

We observed that 5 months of ER did not affect absolute muscular strength in old rats (Fig. 1). Absolute muscular force increased in ER-fed rats compared with both AL diets, regardless of the nature of the proteins in the diet $(+12 \%$ for ER-CAS $v$. AL-CAS, $P<0.05$ and $+23 \%$ for ER-WP $v$. AL-WP, $P<0.001)$. Moreover, muscle strength tended to be significantly higher in ER-WP rats compared with ER-CAS animals $(P=0.09)$ and was significantly increased in ER-WP old rats compared with PER-WP animals $(+16 \%, P<0 \cdot 05)$. Furthermore, muscle strength-to-body ratio was significantly increased in the PER

Table 3. Nitrogen balance and absolute synthesis rate of muscle proteins (tibialis anterior) of ad libitum (AL)-fed, protein and energy-restricted (PER) and energy-restricted (ER) aged rats receiving whey proteins (WP) or casein (CAS) as the protein source*

(Mean values with their standard errors, $n 7-9$ rats)

\begin{tabular}{|c|c|c|c|c|c|c|c|c|c|c|c|c|}
\hline & \multicolumn{2}{|c|}{ AL-CAS } & \multicolumn{2}{|c|}{ AL-WP } & \multicolumn{2}{|c|}{ PER-CAS } & \multicolumn{2}{|c|}{ PER-WP } & \multicolumn{2}{|c|}{ ER-CAS } & \multicolumn{2}{|c|}{ ER-WP } \\
\hline & Mean & SEM & Mean & SEM & Mean & SEM & Mean & SEM & Mean & SEM & Mean & SEM \\
\hline $\mathrm{N}$ balance $(\mathrm{g} / \mathrm{kg}$ per $\mathrm{d})$ & 0.34 & 0.14 & 0.37 & 0.09 & $0.23 \dagger$ & 0.13 & $0.33 \ddagger$ & 0.10 & $0.36 \S$ & 0.16 & $0.42 \S$ & 0.16 \\
\hline Muscle protein ASR $(\mathrm{mg} / \mathrm{d}) \|$ & $6 \cdot 7$ & $1 \cdot 2$ & $8 \cdot 1 \ddagger$ & $2 \cdot 7$ & $4.0 \dagger$ & 0.4 & $5 \cdot 5 \dagger \ddagger \|$ & $1 \cdot 2$ & $4 \cdot 7^{*} \dagger$ & 0.6 & $6 \cdot 3 † \ddagger \|$ & $1 \cdot 1$ \\
\hline
\end{tabular}

ASR, absolute synthesis rate.

* Two-way ANOVA was performed to discriminate among effects of the experimental nutritional conditions, i.e. protein (WP/CAS), energy restriction (ER; AL/PER/ER) and their interactions.

† Mean values were significantly different between AL group with the same dietary protein source in the diet $(P<0.05$ by Fisher's test).

¥ Mean values were significantly different between CAS group with the same protein quantity in the diet $(P<0.05$ by Fisher's test).

$\S$ Mean values were significantly different between PER group with the same dietary protein source in the diet $(P<0.05$ by Fisher's test).

$\|$ Mean values of protein and ER were significantly different for muscle protein ASR $(P<0.05$ and $P<0.05$, respectively). 




Fig. 1. Muscular performance and muscular performance:body mass ratio using the grip force test in ad libitum (AL-casein (CAS), $\square$; AL-whey protein (WP), $\square$ )-fed, protein and energy-restricted (PER-CAS, $\square$; PER-WP, $\square$ ) and energy-restricted (ER-CAS, 口; ER-WP, घ) aged rats receiving whey proteins or casein as the protein source. Values are means, with their standard errors represented by vertical bars $(n 9-10)$. Two-way ANOVA was performed to discriminate among the effects of the experimental nutritional conditions, i.e. protein (WP/CAS), ER (AL/PER/ER) and their interactions. A significant effect of ER $(P<0.05)$ was observed for muscle strength $(\mathrm{N} / \mathrm{kg}$ body weight (BW)). ${ }^{*}$ Mean values were significantly different in the $\mathrm{AL}$ group with the same dietary protein source in the diet $(P<0.05$ by Fisher's test). † Mean values were significantly different in the PER group with the same dietary protein source in the diet $(P<0.05$ by Fisher's test).

groups compared with AL controls ( $+30 \%$ for PER-CAS $v$. AL-CAS, $P<0 \cdot 01$ and $+31 \%$ for PER-WP $v$. AL-WP, $P<0 \cdot 01$ ) but was increased to a much greater extent in the ER rats $(+46 \%$ for ER-CAS $v$. AL-CAS, $P<0.0001$ and $+49 \%$ for ER-WP $v$. AL-WP, $P<0 \cdot 0001)$. Interestingly, ER animals differed from PER animals only with old rats being fed the WP diet $(+14 \%$ ER-WP rats $v$. PER-WP rats, $P<0.05)$.

\section{Discussion}

The present study aimed to define (i) the effect of ER on muscle metabolism and strength and (ii) the effect of protein source on ER action on the muscle. ER was associated with decreased muscle mass and protein synthesis rates but increased muscle strength. In addition, we showed that 'fast protein', i.e. WP, was more efficient than CAS in maintaining muscle protein synthesis in ER and PER old rats. Moreover, high intake of WP associated with ER demonstrated beneficial effects on skeletal muscle strength.

One of the most important results was that long-term ER increased muscle strength in aged rats. The decline in muscle strength during ageing is due to a decrease in both muscle mass and muscle-specific force, i.e. intrinsic muscle function $^{(28-30)}$. Although muscle strength was evaluated in living animals in the present study, the present results and corroborated with several authors who assessed muscle strength indirectly by measuring parameters such as muscle mass or muscle-specific force. ER has been found to reduce the rate of age-related skeletal muscle mass loss in soleus, tibialis anterior, extensor digitorum longus and hindlimb muscles in rats $^{(31-33)}$. In addition, lifelong $\mathrm{ER}$ was able to attenuate muscle fibre loss with age in the epitrochlearis muscle fibre (type II) but failed to do so in the soleus muscle (type I) ${ }^{(34-37)}$. ER also reduced the age-associated decrease in muscle-specific force in extensor digitorum longus muscle maintaining the intrinsic force-generating capacity of muscle fibres ${ }^{(38)}$. There are various mechanisms by which ER may benefit skeletal muscle function with age. Several studies strongly suggest that a variety of advanced glycation end-products and lipo-oxidation end-products accumulate in tissues with increase in age, in particular in long-lived proteins such as myofibrillar proteins ${ }^{(39,40)}$. Interestingly, advanced glycation end-products derived from glucose display a profound negative effect on myosin function and muscle strength $^{(41,42)}$. Lifelong ER is able to reduce the age-related rise in protein glycation ${ }^{(40)}$. Other beneficial effects of ER include reductions in DNA deletions and increases in proteasome and mitochondrial functions ${ }^{(35,43)}$, all of which could positively affect muscle contractile function and therefore improve muscle strength.

The intake of WP during the ER and AL conditions was able to improve protein synthesis rate in comparison with the corresponding CAS groups. Both animal and human studies ${ }^{(11,16)}$ suggest that a significant increase in plasma AA is required in aged individuals in order to stimulate body protein synthesis, particularly in skeletal muscle. These observations highlight the importance of maintaining a sufficiently high protein intake during ageing to counteract the negative effect of ageing on protein metabolism, especially in ER conditions. Maintained protein intake levels during ER could cooperate to improve muscle protein deposition and function. Several reports strongly suggest that a 'fast' protein might be more beneficial than a 'slow' protein to increase protein gain and consequently limit body protein losses in elderly animals ${ }^{(15,44)}$ However, research studying the impact of dietary protein digestion rate on protein metabolism has only focused on whole-body protein synthesis ${ }^{(13-15,44)}$, and consequently the impact on skeletal muscle protein synthesis remains unknown.

In the present study, muscle protein synthesis was increased with WP dietary protein in AL-fed old rats. Furthermore, although dietary restrictions decreased muscle protein synthesis, regardless of the ER or PER conditions, WP rats displayed a greater muscle protein synthesis rate than their CAS counterparts. Overall, this effect may participate in preventing muscle loss in PER-WP and ER-WP old rats. In the AL-WP old rats, the unchanged muscle mass compared with AL-CAS rats despite the higher protein synthesis rate would suggest that muscle proteolysis was also enhanced in this group, resulting in higher muscle protein turnover. This result contrasts with previous whole-body studies supporting the idea that 'fast' proteins do not affect protein breakdown ${ }^{(13)}$. Nevertheless, the previous work focused on postprandial effects of 'fast' proteins on whole-body protein metabolism. Taken together, we postulate that the muscle protein degradation rate has to be determined to actually conclude about the effect of PER and ER on muscle protein turnover, although at this point precise measurement of muscle protein degradation is technically difficult. 
Variation in postprandial AA availability at muscle level is probably responsible for the observed muscle protein synthesis difference between WP and CAS groups. It has been shown that impairment of protein synthesis in old muscle after meal ingestion $^{(11,12)}$ could be normalised by high levels of dietary $\mathrm{AA}^{(16,45)}$. Dardevet et al. ${ }^{(46)}$ have suggested that deficient postprandial muscle protein anabolism during ageing might result from a decrease in muscle protein synthesis sensitivity to AA, particularly leucine. They found that muscle protein synthesis still responded to the leucine signal in old rats, but the half-maximum effect of AA was observed with two- to three-fold higher AA levels than in young or adult rats ${ }^{(46)}$. Consequently, because old rats are still able to respond normally to higher leucine concentrations, these data suggest that increasing plasma AA may be beneficial to maintaining postprandial stimulation of muscle protein metabolism. Taken together, these observations support the idea that AA availability plays a major role in regulating muscle protein turnover rate and may be critical for aged muscle ${ }^{(47)}$. WP contains a high percentage of leucine in comparison with CAS (14 $v .8 \%$ ). Therefore, WP could be beneficial to stimulate muscle protein synthesis during ageing by rapidly increasing the availability of leucine into this tissue. Nevertheless, a concern of the present study is the measurement of muscle protein synthesis using the flooding dose procedure with a branched-chain AA, although valine, i.e. the AA used as a tracer, is not able to stimulate muscle protein synthesis.

The mixed muscle protein synthesis rate was lower in ER conditions, i.e. PER and ER old rats, regardless of protein source and quantity in the diet. The energy intake in these groups is probably insufficient to sustain the energetic demand related to the protein synthesis process. It is also important to note that muscle mass and muscle strength tended to be higher ( 8 and $9 \%$, respectively) when PER rats were fed chronically with a 'fast' protein. Taken together, these data suggest that dietary proteins may differently regulate muscle protein metabolism depending on digestion and absorption rates and the resulting AA bioavailability. The present findings also showed that this effect is related to energy intake.

The nature and the level of protein and energy intake affected muscle weight differently according to muscle type. In terms of absolute weight, i.e. in $\mathrm{mg}$, the different diets had no effect on the soleus muscle (oxidative) but did affect the tibialis anterior muscle (glycolytic). ASR followed the same pattern, remaining unaffected in the soleus muscle (data not shown). The mechanisms causing differential effects of ER on these two muscles are unclear. Interestingly, glycolytic (type II) fibres are more affected by age than oxidative (type-I) fibres ${ }^{(35,48)}$, which can lead to a greater sensitivity to ER. Moreover, since the soleus muscle is oxidative while the tibialis anterior muscle is glycolytic, it is possible that the use of glucose as substrates by tibialis anterior may be ratelimiting for muscle protein synthesis, in particular in ER conditions $^{(49,50)}$. By contrast, the soleus muscle is equipped to use fatty acids as substrates. It has been proposed that during ER, muscle lipolysis provides a local source of fatty acids in oxidative muscle ${ }^{(51)}$, which might supply sufficient energy to ensure protein synthesis. Further studies are needed to understand these discrepancies. At the wholebody level, nitrogen balance was maintained or even improved in the case of the ER-WP group by ER in old rats, except in the PER-CAS animals. This observation, already described by other authors ${ }^{(23)}$, is remarkable, since ER decreased muscle weight, in particular in the CAS groups. Overall, these data indicated that sparing of body proteins is more efficient when ER used a low intake of WP, i.e. in PER-WP rats, or normal protein intake, i.e. in ER-WP and ER-CAS groups. In addition, the apparent paradox between muscle weight changes and nitrogen balance variations means that nitrogen would be spared in other body areas than in skeletal muscles, e.g. the gut or the liver. Although very little is known about the effects of ER on protein metabolism, the nitrogen balance data showed that the sparing effect of fast proteins or increased protein intake, i.e. ER rats, is partly located elsewhere than in the muscle. PER-WP diet is associated with a higher nitrogen balance together with a greater mixed muscle ASR than the PER-CAS diet. These data would mean that WP protein may be more efficient in sparing proteins in skeletal muscle than CAS during PER. In addition, despite energy restriction, the ER-CAS diet is able to maintain equivalent nitrogen balance as in AL-CAS old rats. However, muscle protein ASR was not improved by ERCAS compared with AL-CAS group. These data showed that during ER in old rats, maintaining protein intake with CAS allowed a protein-sparing effect elsewhere than in the muscle.

In conclusion, the present study suggests a beneficial impact of long-term maintenance of regular protein intake associated with ER on muscle mass and force during ageing. 'Fast' proteins, i.e. WP, were able to maintain muscle mass, protein synthesis and strength in old rats compared with CAS in dietary restriction conditions, particularly in the type II muscles specifically affected by age. These results pave the way to a new strategy to favour muscle anabolism in older people with low energy intake or in people under ER, i.e. obese patients. Quality of protein intake is an important issue to be considered in these situations.

\section{Acknowledgements}

The authors thank Lactalis Industry (Retiers, France) for kindly donating the whey protein. There was no funding. S. W. and A. Z. supervised the study conception and design; data generation, collection, assembly, analysis and interpretation; drafting the manuscript; approval of the final version of the manuscript. C. G., K. S., J. S., C. G., Y. B. and V. P. analysed and interpreted the data, and approved the final version of the manuscript. The authors have no conflicts of interest.

\section{References}

1. Evans WJ (1995) What is sarcopenia? J Gerontol A Biol Sci Med Sci 50, 5-8.

2. Carmeli E, Coleman R \& Reznick AZ (2002) The biochemistry of aging muscle. Exp Gerontol 37, 477-489. 
3. Short KR \& Nair KS (1999) Mechanisms of sarcopenia of aging. J Endocrinol Invest 22, 95-105.

4. Welle S, Thornton C \& Statt M (1995) Myofibrillar protein synthesis in young and old human subjects after three months of resistance training. Am J Physiol 268, E422-E427.

5. Balagopal P, Schimke JC, Ades P, et al. (2001) Age effect on transcript levels and synthesis rate of muscle MHC and response to resistance exercise. Am J Physiol Endocrinol Metab 280, E203-E208.

6. Rooyackers OE, Adey DB, Ades PA, et al. (1996) Effect of age on in vivo rates of mitochondrial protein synthesis in human skeletal muscle. Proc Natl Acad Sci U S A 93, 15364-15369.

7. Guillet C, Zangarelli A, Mishellany A, et al. (2004) Mitochondrial and sarcoplasmic proteins, but not myosin heavy chain, are sensitive to leucine supplementation in old rat skeletal muscle. Exp Gerontol 39, 745-751.

8. Dardevet D, Sornet C, Bayle G, et al. (2002) Postprandial stimulation of muscle protein synthesis in old rats can be restored by a leucine-supplemented meal. J Nutr 132, 95-100.

9. Guillet C, Prod'homme M, Balage M, et al. (2004) Impaired anabolic response of muscle protein synthesis is associated with S6K1 dysregulation in elderly humans. FASEB $J \mathbf{1 8}$, $1586-1587$

10. Volpi E, Sheffield-Moore M, Rasmussen BB, et al. (2001) Basal muscle amino acid kinetics and protein synthesis in healthy young and older men. JAMA 286, 1206-1212.

11. Mosoni L, Valluy MC, Serrurier B, et al. (1995) Altered response of protein synthesis to nutritional state and endurance training in old rats. Am J Physiol 268, E328-E335.

12. Welle S, Thornton C, Statt M, et al. (1994) Postprandial myofibrillar and whole body protein synthesis in young and old human subjects. Am J Physiol 267, E599-E604.

13. Boirie Y, Dangin M, Gachon P, et al. (1997) Slow and fast dietary proteins differently modulate postprandial protein accretion. Proc Natl Acad Sci U S A 94, 14930-14935.

14. Dangin M, Boirie Y, Garcia-Rodenas C, et al. (2001) The digestion rate of protein is an independent regulating factor of postprandial protein retention. Am J Physiol Endocrinol Metab 280, E340-E348.

15. Dangin M, Boirie Y, Guillet C, et al. (2002) Influence of the protein digestion rate on protein turnover in young and elderly subjects. J Nutr 132, 3228S-3233S.

16. Volpi E, Ferrando AA, Yeckel CW, et al. (1998) Exogenous amino acids stimulate net muscle protein synthesis in the elderly. J Clin Invest 101, 2000-2007.

17. Volpi E, Kobayashi H, Sheffield-Moore M, et al. (2003) Essential amino acids are primarily responsible for the amino acid stimulation of muscle protein anabolism in healthy elderly adults. Am J Clin Nutr 78, 250-258.

18. Dangin M, Guillet C, Garcia-Rodenas C, et al. (2003) The rate of protein digestion affects protein gain differently during aging in humans. J Physiol 549, 635-644.

19. Koopman R, Walrand S, Beelen M, et al. (2009) Dietary protein digestion and absorption rates and the subsequent postprandial muscle protein synthetic response do not differ between young and elderly men. J Nutr 139, 1707-1713.

20. Walrand S, Short KR, Bigelow ML, et al. (2008) Functional impact of high protein intake on healthy elderly people. Am J Physiol Endocrinol Metab 295, E921-E928.

21. Pennings B, Koopman R, Beelen M, et al. (2011) Exercising before protein intake allows for greater use of dietary protein-derived amino acids for de novo muscle protein synthesis in both young and elderly men. Am J Clin Nutr 93, $322-331$.
22. Zangarelli A, Chanseaume E, Morio B, et al. (2006) Synergistic effects of caloric restriction together with protein intake on skeletal muscle performance in old rats: a mitochondrial-mediated pathway. FASEB J 20, 2439-2450.

23. Giroud S, Perret M, Stein P, et al. (2010) The grey mouse lemur uses season-dependent fat or protein sparing strategies to face chronic food restriction. PLoS One 5, e8823.

24. Garlick PJ \& McNurlan MA (1998) Measurement of protein synthesis in human tissues by the flooding method. Curr Opin Clin Nutr Metab Care 1, 455-460.

25. Mosoni L, Malmezat T, Valluy MC, et al. (1996) Muscle and liver protein synthesis adapt efficiently to food deprivation and refeeding in 12-month-old rats. $J$ Nutr $\mathbf{1 2 6}$, 516-522.

26. Zangarelli A, Walrand S, Guillet C, et al. (2004) Centrifugationbased isolation of myosin for measurement of its synthesis rate in small muscle samples. Anal Biochem 327, 55-60.

27. Authier N, Gillet JP, Fialip J, et al. (2003) A new animal model of vincristine-induced nociceptive peripheral neuropathy. Neurotoxicology 24, 797-805.

28. Zamboni M, Turcato E, Santana H, et al. (1999) The relationship between body composition and physical performance in older women. J Am Geriatr Soc 47, 1403-1408.

29. Visser M, Harris TB, Langlois J, et al. (1998) Body fat and skeletal muscle mass in relation to physical disability in very old men and women of the Framingham Heart Study. J Gerontol A Biol Sci Med Sci 53, M214-M221.

30. Gonzalez E, Messi ML \& Delbono O (2000) The specific force of single intact extensor digitorum longus and soleus mouse muscle fibers declines with aging. J Membr Biol 178, $175-183$.

31. Luhtala TA, Roecker EB, Pugh T, et al. (1994) Dietary restriction attenuates age-related increases in rat skeletal muscle antioxidant enzyme activities. J Gerontol $\mathbf{4 9}$, B231-B238.

32. el Haj AJ, Lewis SE, Goldspink DF, et al. (1986) The effect of chronic and acute dietary restriction on the growth and protein turnover of fast and slow types of rat skeletal muscle. Comp Biochem Physiol A 85, 281-287.

33. Boreham CA, Watt PW, Williams PE, et al. (1988) Effects of ageing and chronic dietary restriction on the morphology of fast and slow muscles of the rat. J Anat 157, 111-125.

34. Lee CM, Aspnes LE, Chung SS, et al. (1998) Influences of caloric restriction on age-associated skeletal muscle fiber characteristics and mitochondrial changes in rats and mice. Ann N Y Acad Sci 854, 182-191.

35. Aspnes LE, Lee CM, Weindruch R, et al. (1997) Caloric restriction reduces fiber loss and mitochondrial abnormalities in aged rat muscle. Faseb J 11, 573-581.

36. McKiernan SH, Bua E, McGorray J, et al. (2004) Early-onset calorie restriction conserves fiber number in aging rat skeletal muscle. FASEB J 18, 580-581.

37. Wanagat J, Cao Z, Pathare P, et al. (2001) Mitochondrial DNA deletion mutations colocalize with segmental electron transport system abnormalities, muscle fiber atrophy, fiber splitting, and oxidative damage in sarcopenia. FASEB $J \mathbf{1 5}$, 322-332.

38. Payne AM, Dodd SL \& Leeuwenburgh C (2003) Life-long calorie restriction in Fischer 344 rats attenuates age-related loss in skeletal muscle-specific force and reduces extracellular space. J Appl Physiol 95, 2554-2562.

39. Baynes JW (2002) The Maillard hypothesis on aging: time to focus on DNA. Ann N Y Acad Sci 959, 360-367.

40. Cefalu WT, Bell-Farrow AD, Wang ZQ, et al. (1995) Caloric restriction decreases age-dependent accumulation of the glycoxidation products, $\mathrm{N}$ epsilon-(carboxymethyl)lysine and 
pentosidine, in rat skin collagen. I Gerontol A Biol Sci Med Sci 50, B337-B341.

41. Ramamurthy B, Hook P, Jones AD, et al. (2001) Changes in myosin structure and function in response to glycation. Faseb J 15, 2415-2422.

42. Ramamurthy B, Jones AD \& Larsson L (2003) Glutathione reverses early effects of glycation on myosin function. $A m$ J Physiol Cell Physiol 285, C419-C424.

43. Selsby JT, Judge AR, Yimlamai T, et al. (2005) Life long calorie restriction increases heat shock proteins and proteasome activity in soleus muscles of Fisher 344 rats. Exp Gerontol 40, 37-42.

44. Crozier SJ, Kimball SR, Emmert SW, et al. (2005) Oral leucine administration stimulates protein synthesis in rat skeletal muscle. J Nutr 135, 376-382.

45. Mosoni L, Patureau Mirand P, Houlier ML, et al. (1993) Agerelated changes in protein synthesis measured in vivo in rat liver and gastrocnemius muscle. Mech Ageing Dev 68, 209-220.
46. Dardevet D, Sornet C, Balage M, et al. (2000) Stimulation of in vitro rat muscle protein synthesis by leucine decreases with age. J Nutr 130, 2630-2635.

47. Boirie Y, Gachon P \& Beaufrere B (1997) Splanchnic and whole-body leucine kinetics in young and elderly men. Am J Clin Nutr 65, 489-495.

48. Lexell J (1995) Human aging, muscle mass, and fiber type composition. J Gerontol A Biol Sci Med Sci 50, 11-16.

49. Hagopian K, Ramsey JJ \& Weindruch R (2003) Influence of age and caloric restriction on liver glycolytic enzyme activities and metabolite concentrations in mice. Exp Gerontol 38, 253-266.

50. Hagopian K, Ramsey JJ \& Weindruch R (2004) Krebs cycle enzymes from livers of old mice are differentially regulated by caloric restriction. Exp Gerontol 39, 1145-1154.

51. Hagstrom-Toft E, Thorne A, Reynisdottir S, et al. (2001) Evidence for a major role of skeletal muscle lipolysis in the regulation of lipid oxidation during caloric restriction in vivo. Diabetes 50, 1604-1611. 